\title{
Dust Resulting from Tire Wear and the Risk of Health Hazards
}

\author{
Masakazu Yamashita, Shohei Yamanaka
}

Department of Environmental Systems Science, Doshisha University, Kyoto, Japan.

Email: myamashi@mail.doshisha.ac.jp

Received April 12 $2^{\text {th }}, 2013$; revised May 13 ${ }^{\text {th }}, 2013$; accepted June $10^{\text {th }}, 2013$

Copyright (C) 2013 Masakazu Yamashita, Shohei Yamanaka. This is an open access article distributed under the Creative Commons Attribution License, which permits unrestricted use, distribution, and reproduction in any medium, provided the original work is properly cited.

\begin{abstract}
The present study examined the effects of air pollutants on people's health, focusing on dust produced from automobile tires while cars drive on roads. The annual volume of dust resulting from tire wear, calculated based on the number of automobiles registered in Japan, was $1747245.4 \mathrm{~m}^{3}$. To put it simply, this translates to approximately 1.4 times the volume of the Tokyo Dome, a famous Japanese baseball stadium. Particulate substances are categorized into three groups depending on their size, and dust resulting from tire wear is classified into the coarse particle mode along with mold spores, pollen, and dust produced from brake pads. This study examined whether or not tire dust causes health damage similarly to pollen, a particulate substance in the same group. There were $38 / \mathrm{cm}^{2}$ dust particles resulting from tire wear on a busy road in Osaka Prefecture, and this number was larger than that of cedar pollen $/ \mathrm{cm}^{2}(35)$, a cause of hay fever, identified in Hokkaido. The results suggest that tire dust may also adversely affect the health of people if any of its constituents has a toxicity or causes allergies.
\end{abstract}

Keywords: Tire Dust; Automobiles; Health; Allergy

\section{Introduction}

In Japan, the automobile industry was established after World War II. Approximately 60 years have passed since its establishment, and the Japanese automobile industry is now the global leader in this field.

With the development of the Japanese automobile industry, the problem of air pollution caused by automobiles has become serious, and detailed environmental standards have been established in accordance with the law. For example, there are also emission standards for environmental protection, and automobile-related companies, including manufacturers, have implemented efforts to comply with them. However, exhaust gas is not the only substance emitted from automobiles. As a car runs, friction between the tires and road produces dust, and the brake pad is worn each time the brake is applied.

Exhaust gas may be cleaned using a catalyst or filter. However, is there any method to prevent tires and brake pads, which are constantly subject to friction and worn out, from producing dust? Although there is agreement that this type of dust is always being produced, adequate research has not been conducted to examine its effects on the human body.

There are approximately 79 million automobiles in Japan, along with a significant number of motorcycles, and, needless to say, these vehicles have rubber tires. The tires, almost always in contact with the surface of the road, are worn out while driving and each time the car turns and brakes are applied due to friction. When a car has run approximately 20,000 to $30,000 \mathrm{~km}$, a sign will appear on the tread of the worn tires to warn of a slip hazard and prompt a tire change. Naturally, tires, similar to rubber erasers, constantly wear out while being used.

Dust and "rubber shavings" are generated as the tires constantly wear out while automobiles drive on public roads. The F1 and other race courses are a good example in which you can see the tread of a tire as it wears out. As the friction coefficient of a race course is significantly higher than that of a public road, a number of rubber shavings, which resemble large eraser shavings, are left on the sides of the race course.

Although we cannot directly identify rubber shavings on public roads while driving a car, the tires of 79 million automobiles and motorcycles produce a substantial amount of dust every day. However, throughout the world 
including Japan, which has adopted strict environmental standards, little attention has been focused on air pollution due to dust produced from tires, which include synthetic rubber made of petroleum and other substances, as well as antipollution measures [1].

The revision of automobile-related laws, in addition to improvements in car production technology, have prompted automobile manufacturers to produce vehicles that comply with the current strict regulations, including environmental standards on exhaust gas emitted from diesel engines - a long-term social issue. On the other hand, the tires of automobiles, which directly contact the surface of the road, continue to generate dust due to friction. There has been an increase in the number of automobiles, and, unsurprisingly, an increasing amount of tire dust.

Therefore, it is necessary to calculate the amount of dust particles resulting from the friction between the tires and surface of the road at present, and discuss their effects on people's health.

\section{Dust Resulting from Tire Wear}

\subsection{Tires and Constituents}

A tire refers to a ring-shaped object around a wheel that touches, through its tread, the surface of the road or ground and rolls on it. In 1867, rubber was attached to the rim of a wheel for the first time, which caused a shift from metal and wooden rims. Since the development of an air tire for bicycles by Dunlop of Britain in 1888 and a car tire by Michelin brothers of France in 1895, there has been considerable growth in the popularity of air tires, as well as an improvement in their quality, including the capabilities to provide a comfortable ride, grip the ground firmly, and maintain stability.

Since tires use rubber as their primary raw material, the following paragraphs describe rubber and other constituents of a car tire to examine the adverse effects on health of tire dust: natural and synthetic rubber, sulfur, zinc oxide, and carbon black; the present paper discuss tires that contain these substances:

Synthetic rubber

Synthetic rubber is made from petroleum. Crude oil is classified depending on the boiling point: heavy oil $\left(350^{\circ} \mathrm{C}\right.$ or higher), light oil $\left(240^{\circ} \mathrm{C}\right.$ to $\left.350^{\circ} \mathrm{C}\right)$, kerosene $\left(170^{\circ} \mathrm{C}\right.$ to $250^{\circ} \mathrm{C}$ ), and gasoline (approximately $110^{\circ} \mathrm{C}$ or lower). Naphtha, also distilled from crude oil, is the primary ingredient of synthetic rubber, and its boiling temperature is between $30^{\circ} \mathrm{C}$ to $230^{\circ} \mathrm{C}$. Ethylene, propylene, and butadiene are derived from the pyrolysis of naphtha at around $1000^{\circ} \mathrm{C}$, and synthetic rubber is produced by isolating, distilling, extracting, and polymerizing them.

Natural rubber

Natural rubber (NR) is a material whose primary ingredient is cis-polyisoprene $\left[\left(\mathrm{C}_{5} \mathrm{H}_{8}\right)_{\mathrm{n}}\right]$, contained in the sap of gum trees. Latex, soluble organic constituents, included in the sap, is collected, distilled, coagulated, and dried to produce gum. Tire rubber consists of synthetic, and natural rubber at a ratio of $1: 1$.

\section{Sulfur}

Adding a few percent of sulfur to rubber and heating it increases its elasticity because of a cross-linking effect. A larger volume of sulfur produces harder rubber. Heat produced by sulfur cross-links the molecules of rubber to enhance its elasticity and strength.

Zinc oxide

Zinc oxide mainly serves as a vulcanization accelerator (helping sulfur vulcanize rubber). About 40,000 tons of zinc oxide is used annually to produce rubber in Japan. Zinc oxide is used for all kinds of natural synthetic rubber.

Carbon black

Carbon black refers to carbon micro-particles with a diameter of 3 to $500 \mathrm{~nm}$ as an industrial product whose quality is controlled, or soot in a broad sense. Tires are black because carbon black, a common rubber-strengthening agent, is used.

Several kinds of raw material are mixed to manufacture rubber products. A typical example is a mixture of rubber (100), carbon (50), zinc oxide (5), and sulfur (2).

\subsection{Number of Tires Currently Used for Vehicles, Calculated Based on the Number of Vehicles}

The study calculated the number of tires that are currently used for vehicles, based on the number of automobiles owned by people in Japan at present. The Japan Automobile Tire Manufacturers Association publishes data on the number of tires sold each year [2]. As automobile tires are consumables, the sales figures are estimated to be significantly larger than the actual number of tires currently used for automobiles driving on the roads. Therefore, the study calculated the number of tires used at present based on the number of automobiles. According to the Automobile Inspection \& Registration Information Association [3], the number of automobiles owned by people in Japan in 2012 was 79,882,112. This number has been predicted to grow.

Vehicles are classified into automobiles for cargo and public transportation, passenger vehicles, automobiles for special purposes, and motorcycles. In general terms, they are grouped into large, medium, and small trucks, buses, passenger and light cars, and emergency vehicles.

As of the end of December 2012, there were approximately 79 million automobiles in Japan, including some 16.5 million cargo transportation vehicles, 230,000 public transportation cars, 57.5 million passenger cars, 1.6 million automobiles for special purposes, and 3.4 million 
motorcycles. Tires are classified into four groups according to their size: tires for light automobiles, normal vehicles, trucks and buses, and trailers. Table 1 shows the numbers of automobiles in each class [3].

The number of tires used for a vehicle varies depending on the automobile type. The present study assumed that two tires are used for one motorcycle, four tires for a light or ordinary vehicle, ten for a truck or bus, and fourteen for a trailer.

The total numbers of tires of each type used as of 2012 were calculated based on Table 1:

Motorcycle: $2 \times 3,402,405=6,806,810$

Light vehicle: $4 \times 24,756,432=99,025,728$

Normal vehicle: $4 \times 43,350,396=173,401,584$

Truck/Bus: $10 \times 2,790,562=27,905,620$

Trailer: $14 \times 2,463,607=34,490,498$

The total volumes of dust emitted from each type of tire were calculated based on these values.

\section{Calculation of the Volume of Tire Dust}

The numbers of tires of each size for 2012 were calculated, as shown in the preceding paragraph. Based on these values, the volume of tire dust was calculated - the total amount of dust produced from tires until they are replaced with new ones.

The Japanese Road Trucking Vehicle Law stipulates that automobiles must pass an automobile safety inspecttion and are allowed to run on the roads in Japan only when the tread depth of the tires is at least $1.6 \mathrm{~mm}$. The tread depth of a new tire is between 7 and $9 \mathrm{~mm}$ depending on the brand of tire. The study assumed that new tires had an $8-\mathrm{mm}$ tread depth and they were replaced when the depth was $1.6 \mathrm{~mm}$ or smaller. As the mean life expectancy of tires is approximately five years, the volume of tire dust emitted was calculated for a period of five years.

To calculate the volume of dust produced from one tire due to friction, the sizes of tires of motorcycles, light and normal vehicles, trucks, buses, and trailers were measured (shown in Table 2). Varying sizes of tire are available for each type of automobile. In the present study, standard-sized tires were selected. Figure 1 shows tire sizes expressed in metric units [4], based on which the volume of tire dust was calculated using the following method:

Table 1. Number of automobiles with tires of different sizes.

\begin{tabular}{cc}
\hline Tire type & Number of automobiles \\
\hline Motorcycle & $3,402,405$ \\
Light vehicle & $24,756,432$ \\
Normal vehicle & $43,350,396$ \\
Truck/Bus & $2,790,562$ \\
Trailer & $2,463,607$
\end{tabular}

Table 2. Tire sizes in metric units.

\begin{tabular}{cc}
\hline Type of vehicle & Tire size in metric units \\
\hline Motorcycle [5] & $100 / 90,16$ \\
Light vehicle [6] & $165 / 55,15$ \\
Normal vehicle [7] & $225 / 45,18$ \\
Truck/Bus [8] & $295 / 80,22.5$ \\
Trailer [8] & $315 / 80,22.5$ \\
\hline
\end{tabular}

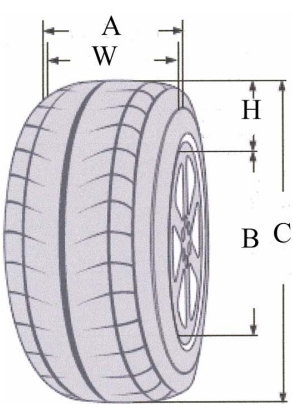

A: Width of the tire

W: Cross-sectional width

H: Cross-sectional height

B: Tire internal (rim) diameter

$\mathrm{C}$ : Tire external diameter

Oblateness $(\%)=\mathrm{H}($ cross-sectional height $) / \mathrm{W}($ cross-sectional width $) \times 100$

Figure 1. Metric system.

The volume of tire dust was calculated using the following formula:

[Decrease in the volume $]=[$ Volume of a new tire $]-$ [Volume of the tire at the time of renewal]

Volume of a new tire: $3.14 \times[\text { Diameter of the tire }]^{2} \times$ [Width of the tire]

Volume of the tire at the time of renewal: $3.14 \times$ $[\text { Diameter of the tire at the time of renewal }]^{2} \times[$ Width of the tire]

As the volume of a tread differs from tire to tire, on calculating the volume of tire wear, it was assumed that the depth of the tire tread was zero when it was replaced. The difference in the volume of a tire was calculated for each type between when it was brand new and immediately before renewal:

Motorcycle: $1136 \mathrm{~cm}^{3}$;

Light vehicle: $1780 \mathrm{~cm}^{3}$;

Normal vehicle: $2880 \mathrm{~cm}^{3}$;

Truck/Bus: $5484 \mathrm{~cm}^{3}$;

Trailer: $5973 \mathrm{~cm}^{3}$.

The volume of tire dust was calculated for each type using the number of tires, calculated based on the number of vehicles:

Motorcycle: $7733 \mathrm{~m}^{3}$;

Light vehicle: $176,266 \mathrm{~m}^{3}$;

Normal vehicle: $4,993,966 \mathrm{~m}^{3}$;

Truck/Bus: 1,666,803 $\mathrm{m}^{3}$;

Trailer: $1,891,459 \mathrm{~m}^{3}$.

A total of $8,736,227 \mathrm{~m}^{3}\left(1,747,245 \mathrm{~m}^{3}\right.$ per year $)$ of tire dust is produced over a five-year period (life-span of a tire adopted in the study). This is equivalent to approximately seven times the volume of Tokyo Dome, a baseball stadium in Tokyo. 


\section{Risk of Health Hazards}

\subsection{Diameter of a Particulate Substance}

In Japan, as environmental efforts to regulate particulate substances, environmental standards were established in 1973, including the definition of suspended particulate substances as particles with a diameter of $10 \mu \mathrm{m}$ or less that stay airborne for a relatively long period and are absorbed by the respiratory system, and general measures for atmospheric environment conservation have been implemented. In recent years, there has been concern over the adverse health effects of microscopic particles with a diameter of $2.5 \mu \mathrm{m}$ or less (SPM 2.5) among suspended particulate matter because they can easily enter deep into the respiratory system and a variety of harmful constituents are absorbed by them or attached to their surface. Western countries are considering setting environmental targets for not only common suspended particulate matter, but also microscopic particles [9]. First, this paper discusses the particle diameter of tire dust, suspended particulate matter, to examine the adverse health effects of dust resulting from tire wear.
The distribution of the diameters of atmospheric particles, as shown in Figure 2, is represented by a curve with three peaks called modes: 1) coarse particle mode consisting of particles with a diameter of 5 to $30 \mu \mathrm{m}$ that are usually produced through a crushing process; 2) accumulation mode of particles with a diameter of 0.15 to 0.5 $\mu \mathrm{m}$ that are generated in the process of condensation or coagulation; and 3) nucleation mode of micro-particles with a diameter of 0.015 to $0.04 \mu \mathrm{m}$ that are created during combustion. Dust particles resulting from tires, brake pads, and the surface of roads, mold spores, and pollen whose diameter is 5 to $30 \mu \mathrm{m}$ (coarse particle range) are classified into the coarse particle mode. Table 3 describes the characteristics of particulate substances classified into the coarse particle mode. There are various shapes and purposes of tires, and the diameter of a tire dust particle is usually between 5 to $30 \mu \mathrm{m}$ (coarse particle range), although harder dust particles are estimated to have a smaller diameter. As tire dust particles do not easily dissolve in water, once absorbed into the human body, they are accumulated there. The distance traveled by atmospheric particles classified into the coarse particle

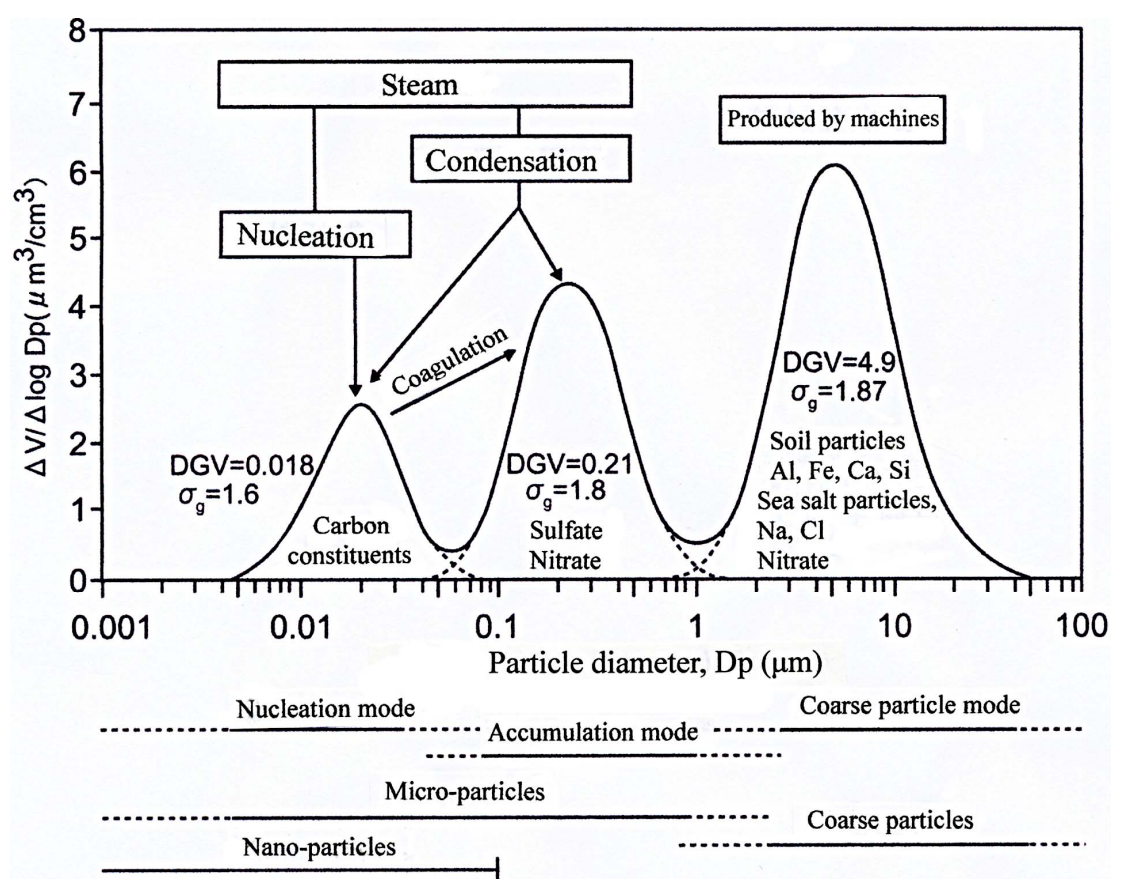

Figure 2. Atmospheric particle modes.

Table 3. Characteristics of particulate matter classified into the coarse particle mode.

\begin{tabular}{|c|c|}
\hline Process of production & Destruction of a large object \\
\hline Methods of production & $\begin{array}{c}\text { Destruction using machines (spallation and pulverization) } \\
\text { Floating of dust particles }\end{array}$ \\
\hline Particulate substances classified into the mode & Mold spores, pollen, and dust resulting from worn brake pads, tires, and roads \\
\hline Water solubility & Nearly insoluble and non-hygroscopic \\
\hline Travel distance & One to several dozen kilometers \\
\hline
\end{tabular}


mode is considered to be one to ten kilometers.

\subsection{Retention and Deposition}

As an ascending current of warm air flows into an upper layer of cold air, particulate substances contained in the warm air usually move away from the source. However, the opposite sometimes occurs - a layer of cold air is under a warm air current. This phenomenon occurs when a warm air mass moves over a cold air mass or ground, or when the air close to the cold ground is cooled during the night. If a cold air mass cannot ascend and flow into an upper layer of warm air for several hours or even days, particulate substances released into the air will also stay near the surface of the ground. This phenomenon, referred to as an inversion layer, occurs in places such as valleys and the spaces between tall buildings in large cities. It may frequently occur or continue for a long period of time under specific geographical and climate conditions. Therefore, the concentration of tire dust in a large city that has tall buildings is assumed to be higher than that in a place without such buildings when there is no difference in the traffic volume because of the inversion layer phenomenon [10].

As just described, the time period particles remain in the air is significantly influenced by the climate and other conditions. Atmospheric particles released from the source of generation are lost from the air through dry deposition when they are near the surface of the ground, and wet deposition if it is raining. Whereas the life span of atmospheric particles in the troposphere is considered to four to five days or one week, particles may stay in the stratosphere for one week or longer.

\subsection{Comparison of Substances with the Same Particle Diameter}

To examine whether or not tire dust causes health damage to the human body, this study focused on the diameter of dust particles - a characteristic of a particulate substance. The distance traveled by a particulate substance and its effects on the human body, including the respiretory system, vary depending on its diameter.

The characteristics of tire dust particles and particulate substances, both classified into the coarse particle mode, were compared to examine the effects of tire dust on health.

The above-mentioned Table 3 includes pollen - a particulate substance that causes hay fever; there has been an increase in the number of hay fever patients. Hay fever is an allergic reaction or inflammation caused by plant pollen attached to the mucosa of the nose, throat, and conjunctiva. When people inhale airborne plant pollen, some of them acquire immunity to the pollen, and an excessive immune response or allergic reaction is caused when they are exposed to the pollen later. Table 4 shows the amount of cedar pollen per area in different prefectures [11]. Hokkaido, Tokyo, Aichi, Nara, and Osaka Prefectures were selected, taking into consideration the maximum and minimum amount of pollen and traffic volume.

To compare the amounts of tire dust and cedar pollen, both were classified into the coarse particle mode, and the volume of tire dust per road area was first calculated. The volume of tire dust in Osaka Prefecture was selected because the number of registered automobiles is large and the total area of roads has been determined.

According to the Automobile Inspection \& Registration Information Association, the number of registered automobiles in Osaka Prefecture as of 2012 was 3,773,365. The total area of roads in Osaka Prefecture, published by the prefectural government in 2003, was $148.75 \mathrm{~km}^{3}$ [12]. These data were used to compare the amount of tire dust and pollen.

As described in Chapter 3, the law stipulates that automobiles must pass an automobile safety inspection and are allowed to run on Japanese public roads only when the tread depth of the tires is $1.6 \mathrm{~mm}$ or larger. The study assumed that new tires had an 8-mm tread depth and they were replaced when the depth was $1.6 \mathrm{~mm}$ or smaller.

(Decrease in the volume $)=($ Volume of a new tire $)-$ (Volume of the tire at the time of renewal);

(Volume of a new tire): $3.14 \times(\text { Radius of the tire })^{2} \times$ (Width of the tire);

(Volume of the tire at the time of renewal): $3.14 \times$ (Its radius at the time of renewal $)^{2} \times($ Width of the tire).

Using these formulas, the volume of dust produced from the tires of automobiles that ran in Osaka Prefecture was $77,226 \mathrm{~m}^{3}$, or $15,445 \mathrm{~m}^{3} /$ per year. As the volume of a tread differs from tire to tire, in the calculation of the volume of tire wear, it was assumed that the depth of the tire tread was zero when it was replaced.

Comparison of the amounts of pollen and tire dust in Osaka Prefecture

Table 4. Amount of cedar pollen per area in different prefectures.

\begin{tabular}{ccc}
\hline Prefectures & Place of measurement $^{*}$ & Measurements in 2012 \\
\hline Hokkaido & Asahikawa City & 35 \\
& Sapporo City & 46 \\
\multirow{2}{*}{ Tokyo } & Chiyoda Ward & 1514 \\
Aichi & Nagoya City & 1739 \\
Nara & Kashihara City & 7811 \\
Osaka & Higashi-osaka City & 2536 \\
\hline
\end{tabular}

The unit of volume of cedar pollen was [the number of particles $/ \mathrm{cm}^{2}$ ] (from the end of January to May). "See Figure 3. 


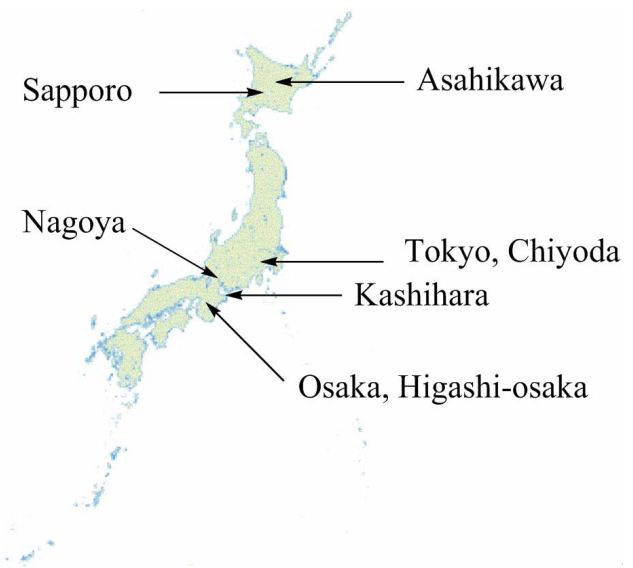

Figure 3. Place of measurement.

According to a measurement conducted in 2012, the amount of cedar pollen in Osaka Prefecture was $2536 / \mathrm{cm}^{2}$, as shown in Table 4. To compare this with the amount of tire dust, the volumetric unit of tire dust $\left(15,445 / \mathrm{m}^{3}\right)$ was changed.

With an assumption that the diameter of pollen and tire dust is $30 \mu \mathrm{m}$, the volume of a tire dust particle was calculated as $2.7 \times 10^{-14} \mathrm{~m}^{3}$. As the total area of roads in Osaka Prefecture was $148.75 \mathrm{~km}^{3}$, the amount of tire dust per area was calculated as 38 , as shown in the following formula:

Volume of tire dust produced per year $\left(\mathrm{m}^{3}\right) /$ Total area of roads in Osaka Prefecture $\left(\mathrm{m}^{3}\right) \times$ Number of dust particles $/ 2.7 \times 10^{-14}\left(\mathrm{~m}^{3}\right)=38 / \mathrm{cm}^{2}$.

The number of tire dust particles was significantly smaller compared to that of cedar pollen $\left(2536 / \mathrm{cm}^{2}\right)$, a cause of hay fever, contained in the air of Osaka Prefecture-the proportion was $1.5 \%$. However, as shown in Table 4, the amount of cedar pollen per area in Asahikawa City, Hokkaido $\left(35 \mathrm{~cm}^{2}\right)$ was smaller than that of tire dust particles in Osaka Prefecture $\left(38 \mathrm{~cm}^{2}\right)$.

Table 4 shows that the amount of cedar pollen in Hokkaido is significantly smaller compared to that of other prefectures. Basically, cedar trees do not grow in Hokkaido, and some cedar pollen produced on the island of Honshu is assumed to be blown to Hokkaido. Since some people in Hokkaido, in which the amount of cedar pollen is relatively small, also suffer from hay fever, dust resulting from tire wear is predicted to significantly affect people's health.

\subsection{Adverse Health Effects from the Viewpoint of Particle Size}

The respiratory system of humans has a function to prevent the entry of foreign substances, such as dust; relatively large-sized dust cannot pass through the nose, and fine dust particles are blocked at the trachea and by bronchial cilia. However, as dust particles with a diame- ter of $10 \mu \mathrm{m}$ or less are not blocked, they reach the alveoli. Even after reaching the alveoli, most of the dust is exhaled, but some dust particles remain in the alveoli. As a person continues to inhale air containing a high concentration of dust, particles accumulate in the alveoli.

Moreover, the inhalation of dust over a long period of time will damage the alveoli and related organs.

Whereas suspended particulate matter is defined as particles with a diameter of $10 \mu \mathrm{m}$ or less, tire dust and other substances classified into the coarse particle mode have a diameter of 5 to $30 \mu \mathrm{m}$. According to this definition, the range of the particle diameter is $25 \mu \mathrm{m}$. Dust particles, suspended particulate matter, with a diameter of $10 \mu \mathrm{m}$ or less, are also produced from some types of tire.

A common respiratory disorder caused by dust is pneumoconiosis. It is usually caused by inhaling dust from soil, metal particles, and other inorganic substances, or mineral dust while working over a long period of time. These dust and fine particles accumulate in the lung, serving as nuclei, and cause fibroplasia and pulmonary fibrosis. In patients with pneumoconiosis, fibrous tissues are formed and the tissues of the alveoli, bronchioles, and blood vessels are destroyed. Patients develop dyspnea, and become vulnerable to pulmonary tuberculosis, secondary bronchitis, and other complications. Agents responsible for causing pneumoconiosis and occupations associated with it are listed in Table 5 [13]. Talc, black lead, and carbon, shown in Table 5, have been reported to cause pneumoconiosis in the process of producing raw materials of tires. As professionals work, these substances accumulate in their bodies little by little every day, and they eventually amount to an enormous volume. In general, the volume of accumulated tire dust is not large enough to cause pneumoconiosis, although the concentration of tire dust contained in the air above heavy traffic roads may be high enough to cause chronic bronchitis and bronchial asthma.

\section{Conclusions}

The present study examined the effects of air pollutants on people's health, focusing on dust produced from automobile tires while cars drive on roads.

Table 5. Substances that cause pneumoconiosis and related occupations.

\begin{tabular}{cc}
\hline Causative agents & Occupations \\
\hline Talc & $\begin{array}{r}\text { Talc pulverization, drug production, rubber } \\
\text { processing, yarn manufacturing, paper } \\
\text { manufacturing, textile production }\end{array}$ \\
Black lead & $\begin{array}{r}\text { Black lead refining, pencil production, preparation } \\
\text { of casting materials, lubricant production, rubber } \\
\text { products manufacturing }\end{array}$ \\
Carbon & Ink production, carbon black production \\
\hline
\end{tabular}


The annual volume of dust resulting from tire wear, calculated based on the number of automobiles registered in Japan, was $1747245.4 \mathrm{~m}^{3}$. To put it simply, this translates to approximately 1.4 times the volume of the Tokyo Dome, a famous Japanese baseball stadium.

Particulate substances are categorized into three groups depending on their size, and dust resulting from tire wear is classified into the coarse particle mode along with mold spores, pollen, and dust produced from brake pads. This study examined whether or not tire dust causes health damage similarly to pollen, a particulate substance in the same group. There were $38 / \mathrm{cm}^{2}$ dust particles resulting from tire wear on a busy road in Osaka Prefecture, and this number was larger than that of cedar pollen $/ \mathrm{cm}^{2}$ (35), a cause of hay fever, identified in Hokkaido. The results suggest that tire dust may also adversely affect the health of people if any of its constituents has a toxicity or causes allergies.

Finally, the study discussed the possible effects of tire dust absorbed into the human body. Tire dust particles with a small diameter enter the human body. As particulate substances of $10 \mu \mathrm{m}$ or smaller reach the alveoli, they may cause a variety of respiratory disorders, such as bronchitis and bronchial asthma.

\section{REFERENCES}

[1] U. Sakurayama, "Jidousha Sangyo Heno Teian," Bungeish, Tokyo, 2007, pp. 11-25.

[2] “The Number of Tires Sold," Japan Automobile Tire Manufacturers Association, 2013. http://www.jatma.or.jp/toukei/

[3] "The Number of Automobiles Owned by People in Japan in 2012," Automobile Inspection \& Registration Information Association, 2013.

http://www.airia.or.jp/number/index.html

[4] Bridgestone Corporation, 2013. http://www.bridgestone.co.jp/

[5] "Motorcycles," HONDA, 2013. http://www.honda.co.jp/motor/

[6] Daihatsu, 2013. http://www.daihatsu.co.jp/index.htm

[7] Toyota, 2013. http://toyota.jp/

[8] Mitsubishi Fuso Truck \& Bus Corporation, 2013. http://www.mitsubishi-fuso.com/

[9] "Evaluation Result of Micro-Particulates for Human Health," The Ministry of the Environment, Japan, 2013. http://www.env.go.jp/air/report/h20-01/index.html

[10] "The Granite Garden: Urban Nature and Human Design," Anne Whiston Spirn, pp. 41-64.

[11] Pollen Observation System, The Ministry of the Environment, Japan, 2013. http://www.env.go.jp/chemi/anzen/kafun/

[12] "Osaka Prefectural Government Statistic Information," Osaka Prefectural Government, 2013. http://www.pref.osaka.jp/toukei/nenkan/tn10-mokuji.html

[13] "Pneumoconiosis, Kanagawa Labor Bureau," The Ministry of Health, Labour and Welfare, 2013. http://kanagawa-roudoukyoku.jsite.mhlw.go.jp/hourei_sei do_tetsuzuki/anzen_eisei/tetsuzuki/jinpai02.html 